\title{
The Value of Aesthetic Class to the Training of Preschool Education Professionals in Normal Universities and the Practice of Realization Path
}

\author{
BAI Xiujie \\ College of Education Science, Baicheng Normal University, Baicheng,137000,China \\ email: 805137560@qq.com
}

Keywords: Aesthetic Class, Preschool Education, Professionals, Realization Path

\begin{abstract}
As the basic education of our country, the development quality of preschool education has a great influence on the development and quality of students. Teachers' quality and professional ability often play a crucial role in promoting the development of teaching activities. In order to cultivate students' comprehensive quality, preschool education in our country has strengthened the opening of aesthetic course in the process of cultivating students.
\end{abstract}

\section{Introduction}

As an important part of China's basic education, preschool education is often regarded as the foundation of education, so it has strong comprehensiveness and guidance in the process of teaching. Based on this, the professional ability and quality of preschool education teachers have become a part of the relevant professional colleges and universities. At present, in order to further improve the quality of preschool education professionals, preschool education teachers strengthen the opening of aesthetic courses, and thus drive the sustainable development of preschool education and achieve higher social benefits.

\section{Application of Aesthetics in Preschool Education Specialty in Teachers Colleges}

Based on the development of the times, our country ' s higher education is facing the new teaching reform . In this background, our country ' s higher education needs to carry out quality teaching actively in combination with the development of the times. In this background, the nature of the basic course of the aesthetic class and the value of the humanistic quality education are being paid attention and gradually shifted to the course teaching of preschool education[1] .

At present, China's basic education reform is also ongoing. Under such a background, China's colleges and universities will further emphasize the importance of aesthetics course and transform it into an important part of preschool education in the process of training teachers. But in fact, there are many problems in the teaching of aesthetics in normal universities. On the one hand, decline of aesthetic teaching status of the institutions of higher learning, lack of unified teaching syllabus, and has not been incorporated into the normal education teaching plan[2]. On the other hand, China's Higher Normal Colleges in the course of teaching, there are aesthetic curriculum old status, lack of scientific concept of authority a comprehensive and effective interpretation of aesthetic knowledge, give timely attention to the society can not many aesthetic phenomena occurring in the transformation period. In such a situation, it will lead to China's higher education teaching work to be able to examine students' aesthetic needs in the process of implementation, which led to the aesthetic gold curriculum in Colleges and universities can stimulate students' interest, and in the actual teaching process, the lack of aesthetics course in theory and practice sure.

Finally, the use of aesthetic education in art subjects in preschool aesthetic courses in normal colleges and universities in China leads to the problem of a single teaching type of aesthetic courses of this kind. Lack of critical elements of the vivid examples, resulting in its actual teaching process can not better carry, integrate a variety of cultural resources. Based on this. In the course of course teaching, teachers colleges and universities in our country need to strengthen the optimization and integration of aesthetic curriculum content, and thus give full play to its aesthetic education function, and realize the optimization of talent training[3]. 


\section{The Function Value of Aesthetic Class}

Cultivating Students' practical Ability in Aesthetic Education. Based on the needs of the development of the times, colleges and universities in our country emphasize the characteristics of the founding process, so as to realize the formation of their own idea and style of running a school. This uniqueness often becomes the difference between higher normal education and ordinary colleges and universities. At present, higher normal colleges and universities in our country in the process of student training and professional skills education. It often pays attention to the cultivation of students' practical skills[4].

As a student majoring in preschool education, due to its particularity in the face of students, its learning process often needs to have a solid preschool practical operation skills. The creation of aesthetics course can achieve the further cultivation of students' aesthetic literacy to the greatest extent, and thus train students' aesthetic skills, so that students have a certain aesthetic level before serving. To ensure that the teaching process can follow the guidance of the aesthetic quality of children.

Integrating a Variety of Cultures. Under the background of the reform of the modern curriculum , how to realize the integration of the content of various subjects becomes the problem that the teaching staff needs to solve urgently . In fact , the organic integration of the content of the multidisciplinary subjects can customize the teaching method and content to the students ' volume to a maximum extent, thus realizing the cultivation of the students ' learning concept before the school age , and stimulating the students ' learning interest to the maximum extent , and promoting the lifelong development of students .

Aesthetic course as a comprehensive subject carrying multidisciplinary knowledge, it is often able to achieve the promotion of comprehensive literacy of college students in the process of promoting teaching. And help students in the later employment process, one person can undertake the teaching of various disciplines, including aesthetic education. In a word, the development of aesthetic courses in teachers' colleges can achieve the integration of various cultures and subjects. And cultivate the curriculum integration consciousness and ability of the future preschool teachers, thus promote the development of the whole preschool education[5].

\section{Measures of Reforming Aesthetics Course in Teachers College}

In order to further promote the improvement of the quality of the aesthetic lesson in higher normal colleges and universities in our country, the enhancement of the skills of the specialized students is promoted, and the reform of the aesthetic lesson needs to be driven in the concrete operation of the higher learning institutions. In this regard, the author summarizes the following measures .

Absorbing Chinese Traditional Cultural Thought. As the teaching content of abstract thinking , aesthetic education is often only meant to be irreversible , so many students cannot grasp their connotation scientifically . In this context , Chinese aesthetic curriculum strengthens the use of traditional cultural elements in the course of teaching[6] .

The adoption of this measure can help students to understand the aesthetic differences between China and the West to the greatest extent, and thus guide the students of preschool education to establish correct aesthetic standards and values at the cognitive level. Finally lead him to identify with the excellent Chinese traditional culture and form a noble moral outlook. Cai Yuanpei, a famous educator of our country, put forward that the educational activities in the process of carrying out the need to achieve aesthetic and intellectual education complement. From this, we can see that the realization of the goal of moral education also needs the development of aesthetic education teaching activities.

At present, China's preschool education professional students often need to face physical and mental immaturity in the process of post employment, children's world outlook and values have not been formed, so students must possess the consciousness of national traditional culture aesthetic values, moral values, and thus ensure that preschool children from China's overall the perception of China's traditional culture, aesthetic taste and the realization of students' moral and ability has been 
significantly improved. Based on this, our normal colleges and universities need to strengthen the teachers for aesthetic curriculum, and absorb China traditional culture in the teaching process, so as to promote the implementation of moral integrity effect, promote preschool education can promote the comprehensive quality of students[7].

In this process, the aesthetic curriculum in Colleges and universities need to realize the organic combination of traditional literature and philosophy, etc., thus realize the beauty of traditional value and low duty, psychological control. In this process, teachers can explain aesthetic content with Chinese literati traditional works, aesthetic pursuit in China the traditional philosophy, thus let the students perceive there during the accomplishment of life and the realm of Chinese traditional aesthetics. Because more related to the harmony of yin and Yang, metaphors and symbols, so teachers can be related to the interception of the content in the Book of Changes in the process of teaching aesthetics teaching, so that students master the aesthetic thinking Chinese.

In addition, teachers in normal colleges also need to sum up and analyze the common cultural events in our society, so as to scientifically grasp the "social beauty" and "the beauty of life". The relevant data survey shows that there are certain aesthetic values in the social issues of our country, and the above value ideas are discussed and analyzed in the aesthetic class. Often it can promote the initiative of teaching activities, but also can greatly guide students to appreciate and analyze beauty, such as teachers guide students to comment on the common beauty and ugliness phenomenon in life. It can often lead students to realize the importance of shaping their own beautiful image, cultivating their aesthetic character, paying attention to public morality, paying attention to their personal civilization and cultivating good aesthetic taste[8].

Close to Professional Reality. Based on the particularity of preschool education in China's higher normal schools, the specialty needs to be different from the aesthetic courses offered by liberal arts majors in comprehensive universities in the process of aesthetic education. In the course of carrying out the aesthetic education course of preschool education specialty, we need to realize the systematical and systematic mastery of aesthetic theory, and gradually infiltrate it into the actual vocational teaching process. Thus realizing the close connection of professional practice, and thus promoting the cultivation of students' related abilities.

At present, preschool education in our country in the development of aesthetic classes, it is necessary to contact with preschool children aesthetic enlightenment guidance, thus promoting the foundation of the curriculum in normal universities. From the point of view of the current aesthetic course teaching of preschool education in normal universities, it will pay too much attention to the income generation of knowledge in the specific implementation process. Therefore, there are some general and abstract problems in the teaching of theory. Moreover, teachers lack the necessary aesthetic literacy and professional knowledge of preschool education. Therefore, the students lack the necessary guidance and development in practical operation and other fields. Based on this. In the course of carrying out aesthetic courses, higher education institutions in our country need to promote the effective combination of aesthetic theory foundation and infant aesthetic enlightenment guidance education, so as to guide future kindergarten teachers to master aesthetic theory. With the help of easy-to-understand words, the essence of infant aesthetic enlightenment education can be explained, and the practical ability of aesthetic education in kindergarten teachers will be improved, and the pertinence and practicability of the classroom will be enhanced[9].

In the concrete aesthetic teaching operation , the teacher can carry out the teaching by means of an exemplary aesthetic education case. In general, the students can understand and master the connotation of all kinds of aesthetic values in the course of the discussion and evaluation of various cases , and realize their own aesthetic cultivation and the promotion of their ability .

Because the teacher is teaching guide, therefore the organization needs to handle the scientific course and value internalization. The kindergarten teachers of our country need further understanding of the aesthetic course connotation and goal in the course of teaching, and further its internalization, thus turn into aesthetic value outlook of science. In the process of teaching specifically, normal universities need to further optimize all kinds of curriculum resources, and on the basis of aesthetic education to enhance the quality of teaching and education, teaching scene, 
events can provide a basis for the teaching work.

In general , the application of vivid teaching cases can let teachers use the vivid case description instead of the traditional abstract theory, so as to guide students to the development trend of the future industry in the simulated teaching situation and solve all kinds of professional development problems .Not only that, by using this teaching method can make students based on the perspective of many kinds of education values to analyze and grasp. In short, teachers need to rationalize in aesthetics teaching process of preschool education in Higher Normal Colleges and universities in the use of various types of kindergarten teaching cases, and on this basis to enable students to understand the characteristics and requirements of children's aesthetic education in the actual case, and internalize the value of children's aesthetic core contains the aesthetic idea and consciousness can be correctly transferred to the children.

Strengthening the Research of Aesthetic Curriculum. Generally speaking, the main purpose of the research and teaching of aesthetic curriculum is to cultivate students' correct aesthetic taste and grasp the true meaning of beauty. And can create beauty. But based on the actual nature of preschool education in China's institutions of higher learning, the aesthetic education of preschool education in China's institutions of higher learning not only needs to let students master the essence of aesthetics. It is also necessary to implement the knowledge of aesthetics into the actual teaching process. In such a situation, the relevant staff need to strengthen the study of aesthetics and strengthen the practice. In practice, students can realize the rational application of aesthetics in teaching practice, and realize the improvement of students' practical ability.

\section{Conclusion}

In order to further promote the quality and efficiency of preschool teaching in normal universities in China. The teaching staff of colleges and universities in our country actively construct the aesthetic curriculum system in the course of course teaching. Based on this, this paper focuses on the application of aesthetics in the preschool education major of normal universities. The author also discusses the function value of aesthetics course and the measures to reform aesthetics course in normal colleges and universities. The author thinks that with the implementation of relevant measures, the quality of preschool teaching in colleges and universities in our country will be greatly developed. And thus to promote the achievement of various benefits, to achieve the quality and quality of preschool education students in China, and lead to higher economic and social benefits. To promote the scientific development of quality education in China.

\section{References}

[1] SU Gaoyan, ZHAO Wen. Comparison and Reflection on the Training Mode of Preschool Education Talents Between China and the United States[J]. Heilongjiang Researches on Higher Education,2013,(11):18-21.

[2] ZENG Bing. Training mode of undergraduate students majoring in preschool education in colleges and universities[J]. Journal of Leshan Normal University,2016,(21):125-130.

[3] WANG Guangyu. A Probe into the Training Objectives and Specifications of Undergraduates Majoring in Preschool Education--Based on the Perspective of Sino-foreign Cooperation in running Schools[J].Journal of Yangzhou University(Higher Education Study Edition),2016,(20)5:47-52.

[4] LIU Jinglan, LIU Shuxiao, XIAO Chengzhi. Research on the Orientation and Quality Specification of the Training Goal of Preschool Education Specialty[J].The Science Education Article Collects,2015,(9)9:33-34+39.

[5] ZHANG Han. The Innovation and Exploration of the Training Mode of "Full-language Education" in Preschool[J].Journal of Inner Mongolia Normal University(Educational Science), 2012, (10):26-28. 
[6] PENG Hailei. The Practical Characteristics of the Curriculum Setup of Preschool Education in American Universities[J].Journal of Open Learning,2013,(2):34-37.

[7] WANG Xiaocheng, ZHANG Peiping, MING Yanhua. The Study and Practice of the Curriculum of Preschool Education in Higher Vocational Colleges[J]. Reform \& Openning, 2013, (8): 155-156+158.

[8] LV Shu, SUN Yong. A Study on the Reform of the Talent training Mode of Preschool Education Specialty in Higher Vocational Colleges Based on the Professional Standards of Kindergarten Teachers;[J].Education Teaching Forum,2014,(21):72-73.

[9] LIU Dehua, WU Rong. Comparison and Enlightenment of the Training Program for Postgraduate Students in China and the United States[J]. Contemporary Teacher Education, 2014, (3): 58-65. 